Agro-Science Journal of Tropical Agriculture, Food, Environment and Extension Volume 20 Number 4 (Special Issue, October 2021) pp. 46 - 51

ISSN 1119-7455

\title{
APPLICATION OF BIOLOGICAL AND DIGITAL TECHNOLOGIES IN RESOLVING THE NEGATIVE EFFECTS OF COVID-19 PANDEMIC ON CROP PRODUCTION IN NIGERIA
}

\author{
Aba S.C. and *Baiyeri K.P. \\ Department of Crop Science, University of Nigeria, Nsukka, Nigeria \\ *Corresponding author’s email: paul.baiyeri@unn.edu.ng
}

\begin{abstract}
The COVID-19 pandemic has wrecked great havoc in many spheres of life, including education, health, economy, and agriculture. This paper $x$-rayed the effects of the pandemic on crop production in Nigeria, and efforts made to proffer viable solutions through the application of biological and digital technologies. The impact of COVID-19 pandemic on crop production was palpable in shortage of farm labour and labour immobility, disruption of agricultural input supply chain (e.g., fertilizers, agrochemicals, and seeds) and food distribution network. These irregularities grossly escalated food insecurity challenges, sparked price hikes, increased hunger and food losses. Considering the impact of COVID-19 pandemic on crop production which invariably extends to farmers' income, food security, family nutrition and health, prompt measures to minimize the onward transmission among key players in crop production and food supply chain are imperative. The application of biological technologies including vaccination, use of natural herbs and spices, organic agriculture options (such as organic manuring, use of botanical protectants, farmers' own seeds, cover cropping, mulching, biofertilizers, etc.), agricultural mechanization, and the digital technologies (mobile phones, remote sensing services, online platforms, robotics and artificial intelligence) would go a long way in resolving the negative effects of the pandemic on crop production in Nigeria. Strict adherences to the recommended public health safety measures (social distancing, compulsory use of face masks in the public, regular hand hygiene, covering of one's mouth when sneezing or coughing, disinfection of high touch surfaces) are crucial in curtailing the spread of COVID-19 infection.
\end{abstract}

Key words: COVID-19 pandemic, crop production, food security, bio-and digital technologies, Nigeria

\section{INTRODUCTION}

The COVID-19 (also known as coronavirus) pandemic is an ongoing global one caused by severe acute respiratory syndrome coronavirus 2 (SARS-CoV-2), which is genetically related to the SARS-CoV-1 virus that caused thousands of deaths between 2002 and 2003 in several countries including China, Hong Kong, Vietnam, Singapore and Canada (Yang et al., 2020; Mirian et al., 2021). The word COVID-19 stands for 'corona virus disease of 2019', depicting the year the outbreak was first identified in the Chinese city of Wuhan in December 2019 (World Health Organization, 2021).

The World Health Organization declared the outbreak a public health emergency of international concern (PHEIC) on 30 January 2020; and the novel infection was later declared a pandemic on 11 March 2020. Since 2009, there have been six (6) of such PHEIC declarations: the 2009 H1N1 (or swine flu) pandemic, the 2014 polio declaration, the 2014 outbreak of Ebola in Western Africa, the 2015-16 Zika virus epidemic, the 2018-20 Kivu Ebola epidemic, and the ongoing COVID-19 pandemic (Mullen et al., 2020).
According to the International Epidemiological Association (2008), a pandemic is an epidemic (or a rapid spread of disease to a large number of people in a given population within a short period) occurring on a scale that crosses international boundaries, usually affecting or killing people on a worldwide scale, of which must be infectious or contagious.

COVID-19 transmits when people breathe in air contaminated by droplets or airborne particles produced when an infected person speaks, sneezes, or coughs (Bochtis et al., 2020). The risk of breathing in these particles is highest when people are in close proximity, but they can be inhaled over longer distances, particularly when confined indoors. Transmission can also occur if splashed or sprayed with contaminated fluids in the eyes, nose or mouth, and rarely via contaminated surfaces (WHO, 2020a). People remain contagious for up to 20 days, and can spread the virus even when they show no symptoms (Bochtis et al., 2020), making the control of the pandemic somewhat challenging.

Symptoms of COVID-19 are highly variable, ranging from asymptomatic to dry cough and fever or mild symptoms such as nasal congestion, sore throat,

Please cite as: Aba S.C. and Baiyeri K.P. (2021). Application of biological and digital technologies in resolving the negative effects of COVID-19 pandemic on crop production in Nigeria. Agro-Science, 20 (4, Special Issue), 46-51. DOI: https://dx.doi.org/10.4314/as.v20i4.6 
loss of smell or taste, as well as, toes and fingers discoloration; serious cases involve shortness of breath, chest pain or pressure, loss of speech and movement (WHO, 2020a). Recommended preventive measures include social distancing, wearing of face mask in public, ventilation and air-filtering, regular, hand washing, covering one's mouth when sneezing or coughing, disinfecting surfaces, monitoring and self-isolation for people exposed or symptomatic. Consequently, most countries including Nigeria implemented some public health safety measures (PHSM) like social distancing, regular hand hygiene, closure of educational institutions, compulsory use of facemasks, ban on public events, border closure, and lockdown (Ilesanmi et al., 2021).

As of $10^{\text {th }}$ June 2021, more than 174 million cases have been confirmed globally, with more than 3.75 million confirmed deaths ascribed to COVID-19 (WHO, 2021), making it one of the deadliest pandemics in history. More than 200 countries and territories have been affected by COVID-19, with major outbreaks occurring in Brazil, Russia, India, Mexico, Peru, South Africa, Western Europe, and the United States (Stawicki et al., 2020). The presence of coronavirus in Nigeria was first reported on 27 February 2020, and since then the cases have risen to over 67,000 and about 1,200 fatalities by the end of November 2020 (Balana et al., 2020). As of $10^{\text {th }}$ June 2021, a total of 167,027 cases have been confirmed, 163,413 cases have been discharged, and 2,117 deaths recorded in the 36 states of Nigeria and the Federal Capital Territory (NCDC, 2021).

The pandemic has resulted in significant social and economic disruptions globally, and has raised issues of racial and geographic discrimination (Mirian et al., 2021). In a bid to curb the spread of COVID-19, governments around the world have responded by implementing travel restrictions, lockdowns/quarantines, workplace hazard controls, business closures, and restriction of several economic and social activities. Unfortunately, these measures have led to widespread supply shortages exacerbated by panic buying, agricultural disruption, and food shortages (Andam et al., 2020). However, there have also been decreased emissions of pollutants and greenhouse gases due to diminished human activities following the lockdowns enforced by various governments (Le Quéré et al., 2020).

In Nigeria, schools and other public areas were partially or fully closed for several months, many events and social gathering were cancelled or postponed, there were total lockdown of businesses and travel restrictions forcing people to remain at home (even without adequate provisions to sustain the food supply chain) amounting to extreme food shortages and insecurity issues. Similarly, at the global level, governments have taken precautionary measures to curtail the spread of the virus, such as quarantine, lockdown, the isolation of infected individuals, travel restrictions, border shutdowns and social distancing. However, these actions proved to have detrimental effects on the economy leading to economic recession and crisis (Mirian et al., 2021).

In this paper, the authors x-rayed the effects of COVID-19 pandemic on crop production in Nigeria, and efforts made to proffer viable solutions through the application of biological and digital technologies. Recommendations presented herein would serve as buffer in case of a future resurgence of the pandemic.

\section{Impact of COVID-19 Pandemic on Crop Production in Nigeria}

COVID-19 pandemic has wrecked great havoc in many spheres of life, including education, health, economy, and agriculture (Ilesanmi et al., 2021). The restrictive measures towards containing the spread of COVID-19 infections have seriously affected the agricultural workforce and jeopardized food security across the globe (Bochtis et al., 2020), and the effects have been more severe in low and middle-income countries like Nigeria. The impacts of COVID-19 pandemic according to Balana et al. (2020) were felt in the form of job and income losses, food insecurity, and rising food prices.

The impact of COVID-19 pandemic on crop production can be categorized under three major scenarios - shortage of labour and labour immobility, disruption of input supply chain (e.g., fertilizers, agrochemicals, and seeds), and lastly food shortages occasioned by travel restrictions and ban on movement of persons and food distribution (including perishable produce like fruits, roots/tubers and vegetables) from the production site to the consumption areas. These irregularities grossly escalated food insecurity challenges, sparked price hikes, increased hunger and food losses. In most countries, the markets for perishable food items were unfavorably affected by workplace closure, particularly at the processing and packaging departments of food companies (Haiying and Chang-wei, 2020). Thus, the transportation of these perishable produce to the markets was hindered as a result of travel restrictions put in place, and this resulted in an increased wastage of the food items (Zhou et al., 2020).

Although food and agricultural activities were seemingly excluded from direct restrictions imposed during the lockdown in Nigeria, the agricultural sector was affected indirectly via its linkages to the rest of the economy. For instance, COVID-19 policy responses severely affected the business of hotels, restaurants, and catering services. Movement restrictions included bans on visiting restaurants, and the lack of a 'food delivery culture' in Nigeria implied a near-total shutdown of urban food services during the lockdown period (Andam et al., 2020).

Furthermore, agricultural production is mostly operated manually in Nigeria due to unavailability of farm machineries. Consequently, periods of peak 
agricultural activity necessitate high demand for labour, but the lockdown and restriction of movement limited access to farmlands by farmers and labourers (Ilesanmi et al., 2021). There were also reports of hunger and malnutrition during the pandemic, which could increase the vulnerability of farm families to COVID-19 causing a further decline in available farm labour.

As a result, the available workforce for cultivating and maintaining farmlands diminished, and agricultural production across the country reduced. For instance, the harvesting period for some perishable crops occurs between March and July, which coincided with the peak of the lockdown in 2020. This resulted in a shortage of labour for harvesting crops, spoilage of ready-to-harvest farm produce, and food shortages in the market, increased cost of food items, hunger and subsequently protest by Nigerians (Ilesanmi et al., 2021).

Similarly, a disruption of the input (seeds, agrochemicals and fertilizer) supply chain and importation resulted in insufficient viable seeds and delayed input procurement/delivery, thereby further limiting crop yields and quality of agricultural produce. This was exacerbated by the reduced money in circulation during the COVID-19 pandemic, and reduced earnings among many individuals, such that most of the available cash was spent on foodstuff rather than farm input (Andam et al., 2020). Food safety and quality were also compromised by increasing rate of COVID-19 cases which reduced available manpower necessitating the engagement of inexperienced ad hoc farm workers leading to poor farm management, poor crop yields and reduced quality of farm produce. In a country where manual labour and rainfed agriculture are the predominant production systems, disruptions in inputs supply chains and labour movement via transport restrictions are bound to have significant negative effects on the agricultural sector (Balana et al., 2020), which is the primary means of livelihood for most Nigerians.

\section{Curbing the Negative Effects of COVID-19 Pandemic on Crop Production through Biological and Digital Technologies}

Considering the impact of COVID-19 pandemic on crop production, farmers' income, food security, family nutrition and health, prompt measures to minimize the further transmission of SARS-CoV-2 among the key players in the crop production and food supply chain are imperative. As documented in the World Health Organization and International Labour Organization recent publication (WHO/ILO Policy Brief, 2021), recommendations were made on measures to prevent the transmission of SARSCoV-2 and manage COVID-19 outbreaks at workplace through remote work directives, restricting worksite entrance to key workers, physical distancing, routine screening, isolation of infected persons, contact tracing and quarantining of contacts, regular worksite disinfection (especially of high touch surfaces), regular hand hygiene, environmental monitoring and appropriate use of personal protective equipment. These measures are quite pertinent, but the complementary application of biological and digital technologies is paramount in the Nigerian crop production scenario considering its huge workforce and labour mobility concerns.

Biotechnology is a broad area of biology, involving the use of living systems and organisms to develop or make products useful to man. The term biotechnology originated from the Greek words 'Bios', meaning 'everything to do with life' and 'Technikos', meaning 'human knowledge and skills'. Thus, the main purpose of biotechnology or the work of biotechnologists in the midst of COVID-19 outbreak, according to Chatterjee (2020), is to produce medicines, drugs, test kits, vaccines, etc. that serve medicinal benefits using new research ideas. On the other hand, digital technologies are electronic tools, systems, devices and resources that generate, store or process data; examples of which include social media, online games, multimedia and mobile phones.

Vaccination as a biotechnology tool has been recommended as one of the safest means of preventing the transmission of SARS-CoV-2 and curtailing the spread of COVID-19 infections (WHO, 2021). Vaccines work by training and preparing the body's natural defenses (the immune system) to recognize, fight and destroy the diseasecausing germs (viruses or bacteria) they target. As of $3^{\text {rd }}$ June 2021, several vaccines (including AstraZeneca/Oxford vaccine, Johnson and Johnson, Moderna, Pfizer/BionTech, Sinopharm, and Sinovac) have been developed and distributed across the globe to curtail the spread of the virus (WHO, 2021).

It is expected that the rollout of these vaccines would play a crucial role in protecting the farm families and the general public from the novel pandemic. However, being vaccinated does not mean to neglect the public health safety measures - wearing facemask in the public must continue, keep regular hand hygiene, ensure good ventilation indoors, obey physical distancing and avoid crowding. As at $10^{\text {th }}$ June 2021 , only a total of $2,151,362$ vaccine doses have been administered in Nigeria (WHO, 2021) in a country of over 210 million people. Considering the limited supply of COVID-19 vaccines at the moment, it is crucial that vaccine distribution be fair and equitable with preference given to workers at higher risk of developing severe COVID-19 illness (like the aged/elderly in the farming communities who dominate the Nigerian farming population) and other workers at elevated risk of SARS-CoV-2 exposure. Similarly, early detection of an infected person and cutting off the transmission route are key points to control the spread of COVID-19, and several diagnostic techniques/kits have been developed via the application of biotechnology (Behera et al., 2020). 
Similarly, naturally derived compounds are worthy therapeutic alternative against several diseases including viral infections, and they are better tolerated in the human body. Singh et al. (2021) identified a host of tropical spices and herbs including turmeric (Curcuma longa L.), ginger (Zingiber officinale Roscoe), black pepper (Piper nigrum L.), sweet basil (Ocimum basilicum L.), garlic (Allium sativum L.), neem (Azadirachta indica A. Juss.), etc. as antiviral agents and immune boosters which could be used in the treatment of the novel COVID-19 disease. The cultivation, production, processing and marketing of these spices and herbs could be up-scaled in this era of the pandemic to satisfy the growing demand. The World Health Organization (WHO, 2020b) recognizes that traditional, complementary and alternative medicine has many benefits and that Africa has a long history of traditional medicine and practitioners that play an important role in providing healthcare and developing new therapies in search of potential treatments for COVID-19, in as much as the efficacy and safety of such therapies are established through clinical trials.

Apart from the prophylactic and therapeutic measures highlighted above, organic agriculture options like the use of animal manures, botanicals, farmers' own seeds, cover cropping, mulching, biofertilizers, etc. would go a long way in sustaining crop farming and minimize dependence on synthetic inputs which are becoming scarce and costly following the restrictive measures imposed to curtail the spread of COVID-19 infections.

Bio-fertilizers are substances that contain microbes, which help in promoting the growth of plants by increasing the supply of essential nutrients. They comprise living organisms, which include mycorrhizal fungi, blue-green algae, and bacteria. Bio-fertilizers as natural fertilizers are known to be eco-friendly, cost-effective, protect the environment from pollutants, and produce longterm effects; hence can be harnessed and utilized in crop production in the era of scarcity of chemical fertilizers and other crop protectants. Mycorrhizal fungi through their extensive thread-like hyphae source nutrients and moisture from organic matter and soil minerals for plant use. Cyanobacteria are photosynthetic bacteria that live in aquatic habitats and moist soils, and are known for nitrogen fixation. Rhizobium is one of the vital symbiotic nitrogen-fixing bacteria, which seek shelter and obtain food from host plants, and in return, provide fixed nitrogen to the plants. Azospirillum is a nitrogen-fixing bacterium that lives around the roots of higher plants (rhizosphere association) and feed on plant exudate. Azotobacter protects the roots from pathogens present in the soil and plays a crucial role in fixing the atmospheric nitrogen. Phosphorus is one of the essential nutrients for plants growth and development. Phosphate solubilizing microorganisms hydrolyze insoluble phosphorus compounds to the soluble form for uptake by plants. Many fungi and bacteria are used for the purpose such as penicillium, aspergillus, bacillus, pseudomonas, etc. A host of these microbes could be harnessed and utilized with other sources of plant nutrients including animal manure for sustained crop production in the scarcity of synthetic fertilizers.

Animal manures are readily available sources of plant nutrients and have long-term benefits on croplands (FAO/IFA, 2000); they maintain soil quality, and maximize water and nutrient-use efficiency of crops. Cover cropping and mulching would suppress weed growth and better conserve the soil against degradation, thereby minimizing the frequency of farm visits and crop maintenance operations. Plant extracts such as neem, garlic, tobacco, papaya, ginger, moringa, etc. could be used to control and manage the pests or diseases of several crops in the absence or scarcity of synthetic pesticides (Rahman et al., 2016). Besides the environmental and health concerns associated with the use of chemical pesticides, they are becoming increasingly costly and unavailable due to the trade restrictions enforced by various governments to curtail the spread of COVID-19 pandemic.

To further reduce the frequency of farm visits and minimize labour mobility, there is need to reduce farm size and optimize resource-use through crop intensification measures (like intercropping/crop diversification, organic manuring, incorporation of crop residues, crop rotation, relay cropping, alley cropping, mulching, etc.), engaging family labour and adoption of home gardens. These measures would minimize the engagement and mobility of farm labourers, and still reduce the frequency of market visits by households (for the purchase of perishable food items like leafy and fruit vegetables) while providing healthy and nutritious food for human consumption. Furthermore, farming activities should be spread out beyond the regular cropping season - governments at all levels should be able to provide functional and affordable irrigation facilities to encourage off-season and well spread cropping pattern that would ensure all-year-round and steady availability of food. This would decongest labour engagements and minimize farmer-to-farmer contact. Similarly, mechanization of farm operations would further minimize the engagement of human labour and reduce the frequency of farm visits.

\section{Use of Digital Technologies in Mitigating the Effects of COVID-19 Pandemic on Crop Production}

In the wake of the multiple challenges facing the agriculture and food sector such as rising insecurity, urbanization, climate change, and now COVID-19 pandemic, the spread of mobile technologies, 
remote sensing services, 'internet of things' (IoT), and artificial intelligence are creating new opportunities to integrate smallholder farmers in a digitallydriven agrifood system by improving their access to information, inputs, market, finance and training (Trendov et al., 2019). Digital agriculture, according to these authors creates systems that are highly productive, anticipatory and adaptable to changes such as those caused by the novel pandemic.

In this era of digitalization, information and communication technologies (ICT) such as mobile phones and computers have revolutionized how people access knowledge and information, do business and use services. The use of mobile applications provides price information to farmers, which can reduce market distortions and help farmers to plan production processes (Baumüller, 2015). With the rise of high-speed internet connections and webenabled smartphones; mobile apps, social media, and other digital engagement platforms have significant potential to improve access to information and services for farmers and their clients. Information on prices and availability of farm inputs could be sourced through these digital platforms and orders placed without physical contact, so also the advertisement of farm produce could be done online to expand the food distribution network.

Through agricultural digitalization, the management of resources throughout the system would become highly optimized and hyper-connected, value chains would become traceable and coordinated at the most detailed level whilst crops and other production systems would be accurately managed to optimal prescription, and this could lead to greater food security, profitability and sustainability. However, many small-scale farmers in developing countries remain isolated from digital technologies and lack the skills to use them.

Agricultural robots ('agrobots') are seen as a key trend that will deeply influence agriculture in the future. In developed countries, field agrobots are already being deployed to help farmers measure, map and optimize water and irrigation use. Fleets of small lightweight robots are now seen as a replacement for traditional high mass tractors, allowing a gradual reduction of compaction, reaeration of the soil and benefits to soil function.

A typical example of digital technology in agrifood systems is the Dino AGROBOT for Agriculture and Viticulture (https://www.naio-technologies.com). The Naiio Technologies team developed agricultural robot to improve working conditions and profitability for farmers. Dino provides a new and effective solution to help farmers tackle the increasing regulations on phytosanitary products, the growing concerns with pesticides, and the lack of workers in the agricultural sector. The Dino weeding robot allows vegetable farmers to manage crop weeding with a high level of precision, while helping them save time all through the season.
Dino is highly effective in weeding field-grown vegetables such as lettuce, carrots, onions, etc., both in raised vegetable beds and in rows.

Digital technologies can also support farmers to anticipate and respond to pest attacks, crop failures and climatic changes through timely weather-based agro-advisory messages. Precision agriculture is an example of an application of the IoT in agriculture. The use of Guidance Systems during planting and fertilizer application can save cost in terms of seed, fertilizer and tractor fuel, and can reduce working hours in the field. Variable Rate Technologies (VRT) and unmanned aerial vehicle (UAV) or drones can also reduce water and pesticide use and reduce labour and resource costs. The VRT allows fertilizer, chemicals, lime, gypsum, irrigation water and other farm inputs to be applied at different rates across a field, without manually changing rate settings on equipment or having to make multiple passes over an area (Sugar Research Australia, 2014).

Over the last few years, the growth in Artificial Intelligence (AI) technology has strengthened agrobased businesses to run more efficiently. Companies that use AI help farmers to scan their fields and monitor every stage of the production cycle. AI technology is transforming the agricultural sector, as farmers can depend on the data that satellite or UAV record to determine the state of their farm rather than walking all the distance. AI can improve resource use, support early decision-making through predictive models and maintain 24/7 monitoring systems.

Access to the internet remains the most critical component for unlocking the possibilities of new technologies. Across the globe, smartphones dominate in terms of time spent online and could enhance the agrifood sector of most developing countries. They create opportunities to access information and services through mobile applications, online videos and social media. Sites like Facebook, Twitter and YouTube present a cost-effective means of communication among smallholder farmers and other key agricultural stakeholders such as extension officers, agro-dealers, retailers, agricultural researchers and policymakers.

However, there are some basic conditions that must exist for the effective use of digital technologies and for digital transformation of the agriculture and food sector. These include infrastructure and connectivity (mobile subscriptions, network coverage, internet access, and electricity supply), affordability, educational attainment (literacy, ICT education) and institutional support (Trendov et al., 2019). Unfortunately, these basic conditions are grossly lacking in most remote agrarian communities in Nigeria. The use of digital technologies requires basic literacy and numeracy as well as special technical knowledge and skills; however, the most critical component for unlocking the possibilities of digital technologies use is access to the internet. 
In conclusion, rather than enforcing lockdown and restriction of businesses/movement, the application of biological technologies including vaccination, use of natural herbs and spices, organic agriculture options (such as manuring, use of botanical protectants, farmers' own seeds, cover cropping, mulching, bio-fertilizers, etc.), agricultural mechanization, and the digital technologies (mobile phones, remote sensing services, online platforms, robotics and artificial intelligence) would go a long way in resolving the negative effects of the pandemic on crop production in Nigeria. Strict adherences to the recommended public health safety measures (social distancing, compulsory use of face masks in the public, regular hand hygiene, covering of one's mouth when sneezing or coughing, disinfecting of high touch surfaces) are very crucial in curtailing the spread of COVID-19 infection.

\section{REFERENCES}

Andam K., Edeh H., Oboh V., Pauw K. and Thurlow J. (2020). Impacts of COVID-19 on food systems and poverty in Nigeria. Adv. Food Secur. Sustain., 5, 145-172. DOI: $10.1016 /$ bs.af2s.2020.09.002

Balana B., Oyeyemi M., Ogunniyi A. et al. (2020). The effects of COVID-19 policies on livelihoods and food security of smallholder farm households in Nigeria: Descriptive results from a phone survey. International Food Policy Research Institute (IFPRI) Discussion Paper 01979. p. 34. Available on 134391.pdf (ifpri.org)

Baumüller H. (2015). Assessing the role of mobile phones in offering price information and market linkages: The case of $\mathrm{m}$-farm in Kenya. EJISDC, 68 (6), 1-16

Behera B., Mishra R. and Thatoi H. (2020). Recent biotechnological tools for diagnosis of corona virus disease: A review. Biotechnol. Progr., 37 (1), 3078. DOI: $10.1002 /$ btpr.3078

Bochtis D., Benos L., Lampridi M. et al. (2020). Agricultural workforce crisis in light of the COVID19 pandemic. Sustain., 12, 8212. DOI: $10.3390 /$ su 12198212

Chatterjee P. (2020). COVID-19 pandemic has unveiled the importance of biotechnologists. Available at https://www.biotecnika.org/2020/05/biotechnologists -covid19-pandemic-role-of-biotech-industry/

FAO/IFA. (2000). Fertilizers and their use. Food and Agriculture Organization of the United Nations and the International Fertilizer Industry Association, Rome, Italy

Hai-ying G. and Chang-wei W. (2020). Impacts of the COVID-19 pandemic on vegetable production and countermeasures from an agricultural insurance perspective. J. Integr. Agric., 19 (12), 2866-2876

Ilesanmi F., Ilesanmi O. and Afolabi A. (2021). The effects of the COVID-19 pandemic on food losses in the agricultural value chains in Africa: The Nigerian case study. Public Health Pract., 2, 100087. DOI: 10.1016/j.puhip.2021.10008

International Epidemiological Association (2008). A Dictionary of Epidemiology. Porta M. (ed.), Oxford University Press, p. 179
Le Quéré C., Jackson R., Jones M. et al. (2020). Temporary reduction in daily global $\mathrm{CO}_{2}$ emissions during the COVID-19 forced confinement. Nature Climate Change, 10, 647-653. DOI: $10.1038 / \mathrm{s} 41558-020-0797-\mathrm{x}$

Mirian O., Danjuma Y. and Amaonyeze N. (2021). Impact of corona virus disease-2019 (COVID-19) pandemic on social lives and interactions of Nigerian citizens. Arch. Med., 13 (3), 15

Mullen L., Potter C., Gostin L., Cicero A. and Nuzzo J. (2020). An analysis of international health regulations emergency committees and public health emergency of international concern designations. BMJ Glob. Health, 5, e002502. DOI: 10.1136/ bmjgh-2020-002502

NCDC. (2021). Update of COVID-19 pandemic. The Nigeria Centre for Disease Control (NCDC) Coronavirus COVID-19 Microsite. Available at https://covid19.ncdc.gov.ng

Rahman S., Biswas S., Barman N. and Ferdous T. (2016). Plant extract as selective pesticide for integrated pest management. Biotechnol. Res. J., 2 (1), 6-10

Singh N., Kumar P., Jyoti and Kumar N. (2021). Spices and herbs: Potential antiviral preventives and immunity boosters during COVID-19. Phytother. Res., 35 (5), 2745-2757. DOI: 10.1002/ptr.7019

Stawicki S., Jeanmonod R., Miller A. et al. (2020). The 2019-2020 novel coronavirus (severe acute respiratory syndrome coronavirus 2) pandemic: A joint American College of Academic International Medicine-World Academic Council of Emergency Medicine, Multidisciplinary COVID-19 Working Group Consensus Paper. J. Glob. Infect. Dis., 12, 47-93

Sugar Research Australia. (2014). Information Sheet IS14017

Trendov N., Varas S. and Zeng M. (2019). Digital technologies in agriculture and rural areas. Food and Agriculture Organization of the United Nations Briefing Paper, Rome, Italy

WHO (2020a). Mask use in the context of COVID-19: Interim guidance. Available at https://apps.who.int/iris/handle/10665/337199

WHO (2020b). WHO supports scientifically-proven traditional medicine. The World Health Organization Regional Office for Africa. Accessed 16 Jun. 2021 from: https://www.afro.who.int

WHO (2021). World Health Organization coronavirus (COVID-19) dashboard. Accessed 11 Jun. 2021 from: https://covid19.who.int

WHO/ILO Policy Brief (2021) Preventing and mitigating COVID-19 at work. Policy Brief 19 May 2021

World Health Organization. (2021). COVID-19 advice for the public: Getting vaccinated. Accessed 10 Jun. 2021 from: https://www.who.int/emergencies/diseases/ novel-coronavirus-2019/covid-19-vaccines/advice

Yang Y., Peng F., Wang R. et al. (2020). The deadly coronaviruses: The 2003 SARS pandemic and the 2020 novel coronavirus epidemic in China. J. Autoimmun., 109, 102434. DOI: 10.1016/j.jaut.2020.102434

Zhou J., Han F., Li K. and Wang Y. (2020). Vegetable production under COVID-19 pandemic in China: An analysis based on the data of 526 households. $J$. Integr. Agric., 19 (12), 2854-2865 